\title{
Re-conceptualizing the development of agency in the school mathematics classroom
}

\section{Raymond Brown}

School of Education and Professional Studies, Griffith University, Gold Coast, Australia

\begin{abstract}
A question that confronts teachers of mathematics is how best to establish in their classrooms a space where students can participate more fully in the curriculum. This article explores the development of agency in the school mathematics classroom. Using data from a variety of classroom contexts, this article employs sociocultural constructs of theorists such as Vygotsky (1981), Wertsch (1991), and Wenger (1998) to examine teacher and student activity during classroom interactions. A specific focus of this examination is the development of student agency. In particular, I explore practices that recognize the tension between the agency of the people teaching and learning the mathematics and the agency of the discipline that accredits and conventionalizes ways of knowing and doing the mathematics. The article concludes that it is in the teacher-student negotiation of coming to know and do mathematics that the development of student agency can be actualized.
\end{abstract}

\section{Introduction}

The majority of mathematics classrooms are situated in institutions that perpetuate typical constructions of teacher and student agency where the teacher is constructed as the authoritative dispenser of disciplinary knowledge and skill and the student as being the passive recipient of that knowledge and skill (Boaler, 2002). As student agency is central to the quality of the learning of mathematics (Boaler, 2008), mathematics educators must consider how best to conceptualize a form of shared agency in the classroom that promotes student learning. This article re-conceptualizes the development of agency in the school mathematics classroom by exploring teacher and student practices that mediate activity in the mathematics curriculum.

\section{A notion of agency}

The concept of agency is core to the teaching and learning of mathematics. It speaks to the capacity of individuals to plan, implement and evaluate the attainment of a goal, (Hernandez \& Iyengar, 2001) and to exert influence in their mathematics context (Boaler, 2002). From a sociocultural point of view, the agency plays an important mediating role in the development of a person's way of being, seeing and responding in the world (Edwards, 2001). This understanding of agency suggests that situating teaching within particular pedagogies that 
(a) incorporate student interest, (b) are sensitive to the development of learner identities, and that (c) employ group work and discussion, improves student learning. It also highlights the tension between teachers' and students' roles in classroom learning and the meditational means (knowledge and skills) that they have access to (Wertsch, 1991). From this point of view, issues which affect the organization of the classroom (such as authority, membership, and norms which privilege certain ways of thinking and acting) are seen as essential aspects of teaching and learning. One sociocultural approach to teaching and learning mathematics that acknowledges this sense of agency is Collective Argumentation.

\section{Collective argumentation}

The work of Max Miller (1987) provides a base for helping teachers to understand how agency in the classroom may be re-conceptualized through the processes of argumentation. According to Miller, the processes of argumentation are underpinned by three cooperation principles. Using the term argumentation in a broad sense to include any 'type of discourse in which the principle goal is to find collective solutions to interindividual problems of coordination' (Miller, 1987, p. 231), the first principle focuses on coordinating the contributions of participants so that a set of collectively valid statements (i.e., statements that need no further questioning regarding their relevance to a given argumentation) can be agreed on. Miller refers to this coordination device as the principle of "generalizability" and describes its function as formulating the conditions which a statement must fulfill in order to be justified.

The realm of the collectively valid in the group, however, is not static and can be changed as a result of intra-group interactions. The changes that may result from these interactions are not arbitrary, but conform to the principle of "objectivity." This principle states that if a statement cannot be denied, it belongs to the realm of the collectively valid regardless of whether it supports or rejects a participant's point of view. The third principle is that of "consistency." According to this principle, mutually exclusive points of view must not "enter into or (once they have been discovered) must not remain in the realm of the collectively valid" (Miller, 1987, p. 234).

For Miller, these principles provided a mechanism whereby agreement building and mutual understanding can be developed through personal and social influences. Through these influences Miller maintained that collective learning environments can be established which have the potential to advance students' awareness in the classroom. However, to utilize the tension between the agency of teacher and students in the classroom and the discipline of mathematics to bring about deep learning, this agreement building needs to be explicitly recognized and complemented with a principle of "consensus" and a principle of "recontextualization" (Brown \& Renshaw, 2000).

In line with the work of Miller, a principle of "consensus" requires that all members of a group understand an agreed approach to solving a problem. If a member of the group does not understand, there is an obligation on that student to seek clarification, and an obligation on the group to assist (Brown \& Renshaw, 2000). A principle of "recontextualization" involves students re-presenting the group agreed response to a task to the other members of the class for discussion and validation. Communicating to the class challenges students to rephrase their ideas, to defend their thinking, and to reassess the validity of their thinking in terms of the discipline of mathematics (Lampert, 1990). 
The above cooperation principles can be developed into a model of shared agency (see Figure 1) to scaffold teacher and student activity in the mathematics classroom so that learning becomes personally responsive and socially assisted through having students share with the teacher in the agency of the classroom. The understanding of shared agency presented in this model is informed by Brown and Renshaw (2006b) who focus the notion of agency on the students and the teacher actively sharing the learning contexts of the classroom in ways that support student interest, are sensitive to the development of learner identities, and that employ group interaction and discussion.

The model presents the principles of argumentation as five interactive practices - representing, comparing, explaining, justifying and agreeing - necessary for coordinating the interactions

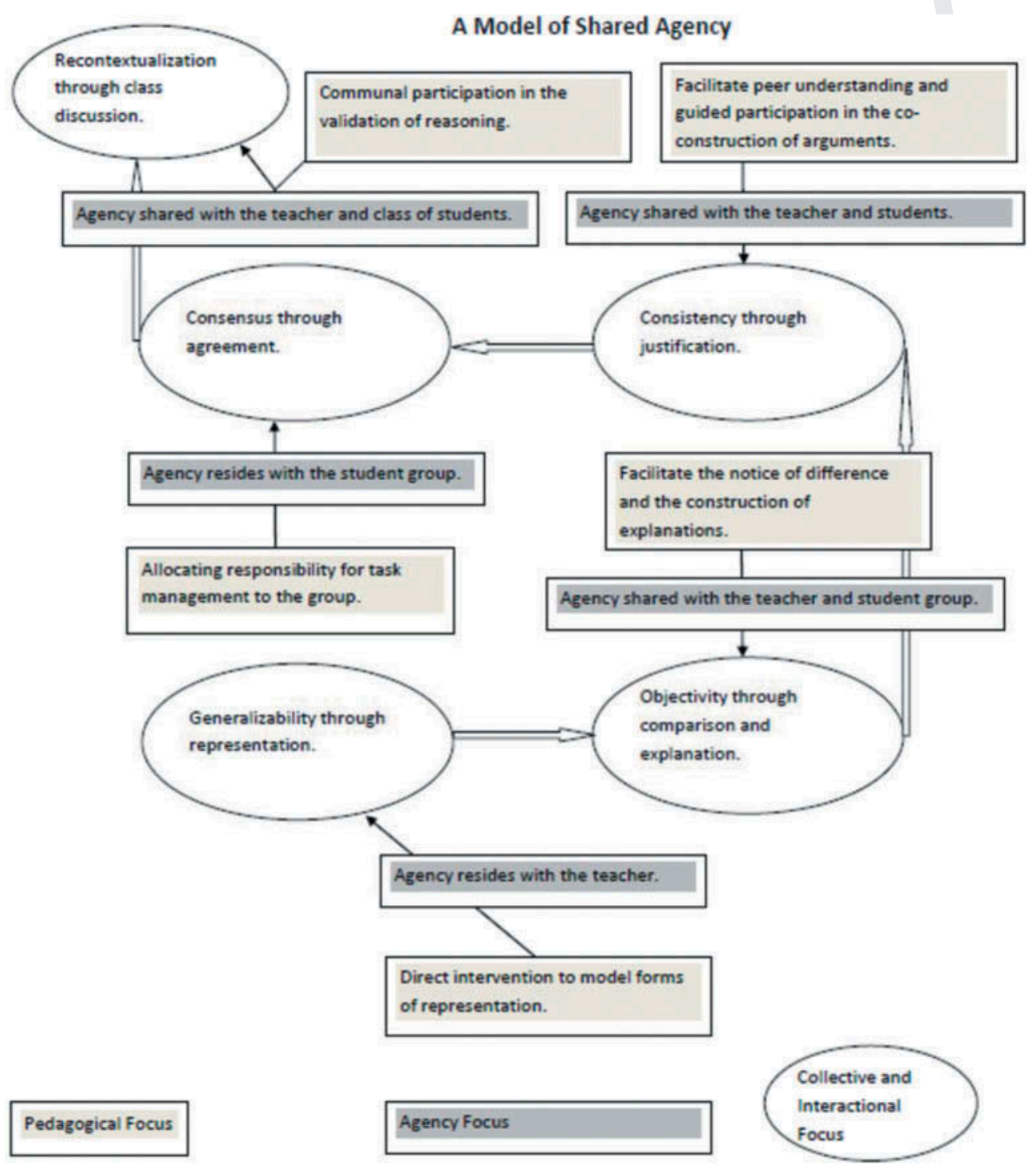

Figure 1. The model of shared agency embedded within a classroom culture which enables pedagogical and interactional support systems to scaffold cognitive development. 
between the teacher, students and the discipline of mathematics along with a series of pedagogical and interactional supports that enable the teacher and students to share in the agency of the classroom. How these processes and supports relate to the principles of argumentation is outlined in Figure 1 where the light shading draws our attention to the pedagogical focus and the dark shading to the agency focus for each principle.

\section{"Generalizability" through representing}

When students represent a personal response to a task, they are more likely to participate in any discussion that follows (Pressley, Gaskins, Solic, \& Collins, 2006). Requiring students to represent their ideas provides them with a resource that they may use to ask questions, share ideas and to monitor their understanding. Even if a representation is incomplete it may provide a student with a tool that can be used to understand that different representations of the same task highlight different aspects of a task and that different aspects of a task need to be considered before it can be successfully completed (Hubscher-Younger \& Narayanan, 2003). As such, representation provides students with a contribution to classroom discourse that can be summarized or re-represented by the teacher or other students.

In simple terms, this phase of the model requires a student to represent in the form of a model (using manipulatives), or a diagram, or a symbolic representation such as an equation, their understanding of a mathematics task. For example, with the Year 6 task: "The manager of a supermarket ordered 10 boxes each containing 100 cans of soup. How many cans of soup did the manager order?" Some students might draw a picture of 10 boxes with a label of 100 cans on each box. Some students may represent a number sentence $100 \times 10=1000$. Other students might go beyond the number sentence and write $10^{1} \times 10^{2}=10^{3}$. For further examples of the Model of Shared Agency at work in the classroom see (Brown, 2011, 2009, 2007).

However, as the teacher will often need to assist students to represent their ideas through the use of concrete representations (e.g., blocks), pictorial representations (e.g., a diagram) and symbolic representations (e.g., an equation), agency at this phase of the model resides, mainly, with the teacher whose focus is on incorporating the everyday ideas of students into the activity of the classroom. This may be done by the teacher joining with individual students to ask questions about the student's representation; add to a representation; redirect a student to task information; and to provide a personal representation to challenge a student's ideas.

\section{"Objectivity" through comparing and explaining}

Comparing and explaining ideas to others takes learning from the individual to the cooperative plane of learning and allows students to see what is the same and what is different about their ideas and interpretations. For some students, it can be a challenge to note and to interpret differences between the ideas they communicate. Such challenges can help students to view concepts from different perspectives (Feltovich, Spiro, Coulson, \& Feltovich, 1996). For other students comparing and explaining can be affirming as they see congruence between representations and the ideas they communicate. However, within most classrooms, students operate within a social setting that has discernible structures of 
authority, meaning that some students may simply align with a representation or an explanation that they deem to be authoritative rather than on a representation or explanation that speaks to their understanding (Hubscher-Younger \& Narayanan, 2003).

With our "cans of soup" example the students would compare and explain their representations to each other. Whilst explaining an idea or a representation can be a goal of learning, it must not be the end product. The process of student comparing and explaining needs to be monitored by the teacher to ensure that misconceptions are addressed and that students' ways of thinking relate to each other and to the conventions of mathematics in a manner constitutive of understanding. As such the agency needs to be shared by the teacher and students at this phase of the model. To do this, the teacher may work with students to note similarities and differences in representations, seek explanations, and challenge students to provide more abstract explanations of their ideas.

\section{"Consistency" through justifying}

If learning in a mathematics classroom is to occur in partnerships between students and between the students and the teacher practices need to involve the gathering and sharing of evidence that satisfies disciplinary constraints associated with coherence and logic (Lampert, 1990). Requiring students to justify ideas enables them to become conscious of others' points of view by allowing processes of thought as well as products to become visible and open to peer critique and guided participation by the teacher. As such, justifying ideas and representations encourages students to question, evaluate, and inquire so that agreement can be attained through understanding rather than through convergence on an authoritative representation, style, or reputation.

In terms of the "cans of soup" task students may justify their representations using utterances such as "diagrams are easier to understand", "the number sentence is more efficient than drawing boxes of soup", "using exponents provides a result without having to calculate using paper and pencil". As the teacher will need to guide students through this process of justifying ideas, agency in this phase of the model resides with the teacher and the students. In order to do this, the teacher may work with students to seek justifications, challenge students to provide more abstract or general justifications for their ideas, and to model inter-subjective norms such as "openness" and "wise-restraint" (see Lampert, 1990).

\section{"Consensus" through agreement}

The collective agreement on a representation or idea that reflects the group's understanding involves the surrender of misconceptions and the selection or co-construction of representations and explanations that reflect each member of the groups understanding of the content being learned. However, before the agreement can be stated, each member of the group must be able to explain some aspect of the representation or idea being selected or co-constructed, if not, there is an obligation on that student to seek understanding and an obligation on the group to provide assistance.

With the "cans of soup" example, guided by the norm that representations and explanations reflect each group member's understanding of the content being learned, some groups of students may choose to represent the solution to the task using diagrams, others using a number sentence, still others using exponents. As the process to reach 
consensus requires obligations on students to either help or to ask for help, the agency may be said to reside with the student group. The teacher may assist the exercise of agency by working with students to seek clarification of ideas from the group, seek personal understandings from group members, and ensure that all group members are participating in the learning of the group. In order to ensure that all group members access these opportunities, it is important that each group be required to validate their group's understanding of the task through a whole class discussion that relates students' ideas and representations to the discipline of mathematics.

\section{"Recontextualization" through whole-class discussion/validation}

Group presentations of their ideas about a task focus on students' recontextualizing their coconstructed understandings to the other members of the class for validation. This recontextualization challenges students to (a) rephrase their ideas in language familiar to the class, (b) explain their ideas in the light of questions from the class, (c) defend their ideas in the light of critique from the class, and, if necessary, (c) reassess the validity of their thinking in the light of the conventions of the discipline of mathematics. Such classroom presentations assist students to engage with the conceptual content of a lesson at a level suitable to their understanding, employ their own prior experiences to contextualize the task, and to distribute the responsibility of their knowing across a group rather than in a fashion that focuses on any one individual (Boaler, 2002). In terms of our "cans of soup" task the teacher may ask the class to compare the different solution pathways, asking "what is the same", "what is different", "what solution pathways are labor intensive", "what require the least mental effort", "which pathways help us see the relationship between the boxes and the cans", and "which pathways are the more efficient, elegant, and align with the discipline of mathematics".

Using students' own language, ideas, and representations to communicate an understanding of a task has the potential to scaffold students' understandings toward higher levels of abstraction and generalization and supports a shift in students' perspectives of what it means to learn mathematics in a school classroom (Boaler, 2002). To assist the development of productive perspectives, the presentation of students' work to the class requires that the students who make up the audience for group presentations be actively engaged in the validation process. Audience engagement needs to center on asking questions about the group's ideas and representations and providing constructive criticism of the conceptual rather than the surface features (e.g., the use of color) of the group's ideas and representations.

In order for this to happen in a manner that assists students to become aware of alternative interpretations, possible misconceptions, and possible refinements to their own understandings, it is important that the agency of the classroom is shared by the teacher and the class of students. In order to do this, the teacher may work with the class to rephrase, paraphrase, and re-represent the contributions of particular groups, draw connections between the contributions of different groups, and refer the class to previous problems and the ways in which similar tasks were approached.

The Collective Argumentation model of shared agency as outlined above has been shown through research to (a) improve the overall quality of teaching and learning in the classroom, and (b) to promote the development of student participation productive of learning mathematics (see Brown, 2017 for a summary of this research). The re-conceptualization of the development of agency in the mathematics classroom can be further informed through 
examining student and teacher perceptions about doing mathematics using an approach to 220 teaching and learning that employs the Collective Argumentation Shared Agency model.

\section{Informing the re-conceptualization of agency in the mathematics classroom}

The examples that follow are from research that employs the Shared Agency Model. The examples of student and teacher perceptions are taken from a large study, conducted over a 3-year time frame, that involved university educators working with primary and secondary school teachers of mathematics from schools located in South-East Queensland, Australia (see Brown, 2017). The aim of the study was to assist teachers to bring about and reflect upon a change in the way they teach mathematics. The study employed a sociocultural methodology based on a "design-experiment" (see Cobb, 2000) and focused on the roles of teacher and students, and the ways of knowing and doing valued in the mathematics classroom.

\section{Student perceptions of learning mathematics when using the shared agency model}

What follows is a summary of the research exploring the social positions (submissive, confident, assertive) that students construct when doing mathematics using the Shared Agency Model (for an account of this research see Brown, 2009; words in italics are the direct utterances of student voices).

When students first encounter the Shared Agency Model in the mathematics classroom their initial perceptions center round the teacher "telling them to". This submission to the agency of the teacher is to be expected and echoes past participation in classrooms where the teacher may have been viewed as the direct transmitter of knowledge and skill to students. However, within weeks, students' reasons for doing mathematics imply that they do it because it is the "way of the group" that the student works with. Initially, it is the group that decides how a math task might be completed, but as time progresses the emphasis on the "way of the group" declines and a focus on the "task solution" - "easy", "appropriate", "a good way" - beings to emerge.

As students become familiar with the Shared Agency Model, the focus on the task solution is complemented with a recognition by students of the contributions of peers and others to sense making in the learning process - for example, "Diana and I agreed" and "I suppose I copied off Katie's group because it was the only one that made sense to me". It is interesting to note that, during this time, students often make a shift in their perception of the role of the teacher where "being told" no longer refers to a teacher direction or transmission, but to expertise: "We didn't do it that way to start off with, until the teacher told me where I went wrong ..."

Over time students' perceptions begin to evidence a stance toward doing mathematics that is more assured and more personal: "I think it was a good idea/way ... " From being "told what to do", either directly or indirectly by the teacher, students begin to assume a more assertive position within the classroom where they start to think for themselves and to assess the quality of their own thinking and the thinking of their group: "I think it was a good way; We didn't get the exact answer but we weren't long off"; and "I think it's right. I tried to explain it well and say what I thought as best I could". 
Taken as a whole, students' reasons for doing mathematics imply a changing form of agentive membership within the classroom community. From initially assuming a submissive position in the collective work of the class that seems quite dependent on teacher directions and to lack confidence, students subsequently move toward a more confident position where their engagement in the learning process is contingent on ideas coming from a range of others (their group, other groups, and the teacher). Perceptions also begin to acknowledge the authorship of ideas: "I suppose I copied ... ", "you (the teacher) told me ... ", and "you told Joel ..." (another student), an important element of developing a shared agency in the mathematics classroom (Brown \& Renshaw, 2006b). In time, students take on the challenge of assessing ideas and solution processes as they move toward assuming more assertive positions within the classroom: "It was easy, the timelines worked, they were quick and showed everything and explained it well".

\section{Teacher perceptions of learning mathematics when using the shared agency model}

What follows is a summary of the research exploring the social positions (authoritarian, authoritative, co-learner) that teachers construct when doing mathematics using the Shared Agency Model (for an account of this research see Brown \& Renshaw, 2006a, words in italics are the direct utterances of teacher voices).

For teachers, using the Shared Agency Model to teach mathematics means letting go of an authoritarian control in the classroom focused on favoring strict adherence to the authority of the discipline, and sharing the direction of lessons with the students. This can be anxiety provoking for many teachers who are used to feeling "in charge and making sure everything ran well in the classroom". In order to persevere with the use of the Shared Agency Model teachers need to address issues related to getting "every child involved in the group" and catering for those "one or two children that no one wants to work with", not "working very much from the text book", and teacher dependence on "tests" when it came to "assessment time".

As these issues are worked through teachers start to see the use of the model to teach mathematics as providing opportunities for teachers to "see immediately where the student is working from", "to build on from that", to provide learning tasks that are "multi leveled and that the students can come in at different levels", and to see discussion at the group and whole class levels as helping the teacher to "see immediately that they (the students) have got the wrong understanding about something". As teachers and students become familiar with the practices of the model teachers' perceptions change from the need to "stand up the front and control the learning" to adopting an authoritative stance where student confidence and respect assist the teacher to "sit with the children when they first attempt the task individually", "go around and check that they (the students) understand the tasks and that they are sharing their ideas", "provoke some ideas with students", "encourage students to be critical about what they are hearing", and to "demand understanding from their peers".

Perceptions of students begin to change from being "empty vessels" to be "filled with knowledge and skills" to being "a learner, a contributor and a collaborator" in the learning process, to knowing "that every student has worth, has something to contribute and that we are all travelling together and we are all learning together". In time there is a movement away from "the quiet, passive classroom" to an "active, buzzing atmosphere that enables students to participate at their own level of understanding and be valued for the contribution they make". 
This article explores the development of agency within mathematics classrooms that employ a sociocultural approach to teaching and learning that offers a collaborative way of re-conceptualizing how teachers and students can share agency in today's educational landscape. Through the "voice" of research reported above, a number of characteristics in the development of "agency" in the mathematics classroom become evident.

Firstly, teachers' and students' ways of exercising agency in the mathematics classroom are embedded in contexts of activity, contexts where students need to be prepared to apply what they know and can do to mathematical tasks, and where teachers need to provide students with opportunities to actively participate in their own learning. Secondly, teachers' capacity to plan, implement and evaluate the attainment of a goal in the mathematics classroom is embedded in interpretive practices (such as representing, comparing, explaining and justifying) that build relationships with students that contribute to the development of student competence and confidence. Thirdly, teachers and students exercise of agency in the classroom is negotiated within the tension between teachers' and students' ways of knowing and doing mathematics and the conventions of the discipline, a tension that can lead to the development of a shared agency in the classroom through the application of principles and practices associated with a sociocultural approach to teaching and learning. In the process, teachers and students may be assisted to reflect upon their practice and to re-conceptualize their exercise of agency in the mathematics classroom.

\section{Disclosure statement}

Q6 No potential conflict of interest was reported by the author.

\section{References}

Boaler, J. (2002). The development of disciplinary relationships: Knowledge, practice and identity in mathematics classrooms. For the Learning of Mathematics, 22, 42-47.

Boaler, J. (2008). Promoting 'relational equity' and high mathematics achievement through an innovative mixed-ability approach. British Educational Research Journal, 34, 167-194. doi:10.1080/01411920701532145

Brown, R. (2007). Exploring the social positions that students construct within a classroom community of practice. International Journal of Educational Research, 46, 116-128. doi:10.1016/j. ijer.2007.09.012

Brown, R. (2009). Teaching for social justice: Exploring the development of student agency through participation in the literacy practices of a mathematics classroom. Journal of Mathematics Teacher Education, 12, 171-185. doi:10.1007/s10857-009-9110-7

Brown, R. (2011). Engaging potential in the mathematics classroom: Moving from practising to be numerate towards practicing mathematical literacy. In C. Wyatt-Smith, J. Elkins, \& S. Gunn (Eds.), Multiple perspectives on difficulties in learning literacy and numeracy (pp. 275-293). Springer International Publications.

Brown, R. (2017). Using collective argumentation to engage students in a primary mathematics classroom. Mathematics Education Research Journal, 29, 183-199. doi:10.1007/s13394-017-0198-2

Brown, R., \& Renshaw, P. (2006a). Transforming practice: Using collective argumentation to bring about change in a year 7 mathematics classroom. In P. Grootenboer, R. Zevenbergen, \& 
M. Chinnappan (Eds.), Identities, cultures and learning spaces (Vol. 1, pp. 99-106). Canberra, AU: Mathematical Education Research Group of Australasia.

Brown, R., \& Renshaw, P. (2006b). Positioning students as actors and authors: A chronotopic analysis of collaborative learning activities. Mind, Culture, and Activity, 13, 244-256. doi:10.1207/ s15327884mca1303_6

Brown, R. A. J., \& Renshaw, P. D. (2000). Collective argumentation: A sociocultural approach to reframing classroom teaching and learning. In H. Cowie \& D. van der Aalsvort (Eds.), Social interaction in learning and instruction: The meaning of discourse for the construction of knowledge (pp. 52-66). Amsterdam, NL: Pergamon/Elsevier Science.

Cobb, P. (2000). Conducting teaching experiments in collaboration with teachers. In A. Kelly \& R. Lesh (Eds.), Handbook of research design in mathematics and science education (pp. 307-333). Mahwah, NJ: Lawrence Erlbaum.

Edwards, A. (2001). Researching pedagogy: A sociocultural agenda. Pedagogy, Culture and Society, 9, 161-186. doi:10.1080/14681360100200111

Feltovich, P. J., Spiro, R. J., Coulson, R. L., \& Feltovich, J. (1996). Collaboration within and among minds: Mastering complexity, individually and in groups. In T. Koschmann (Ed.), CSCL: Theory and practice of an emerging paradigm (pp. 25-44). Mahwah, NJ: Lawrence Erlbaum Associates.

Hernandez, M., \& Iyengar, S. S. (2001). What drives whom? A cultural perspective on human agency. Social Cognition, 19, 269-294. doi:10.1521/soco.19.3.269.21468

Hubscher-Younger, T., \& Narayanan, N. H. (2003). Constructive and collaborative learning of algorithms. Proceedings of the 34th SIGCSE technical symposium on computer science education, 1-58113-648-X, 6-10, Reno, NV.

Lampert, M. (1990). Connecting inventions with conventions. In L. P. Steffe \& T. Wood (Eds.), Transforming children's mathematics education: International perspectives (pp. 253-265). Hillsdale, NJ: Lawrence Erlbaum Associates.

Miller, M. (1987). Argumentation and cognition. In M. Hickmann (Ed.), Social and functional approaches to language and thought (pp. 225-249). London, UK: Academic Press.

Pressley, M., Gaskins, I., Solic, K., \& Collins, S. (2006). A portrait of benchmark school: How a school produces high achievement in students who previously failed. Journal of Educational Psychology, 98, 282-306. doi:10.1037/0022-0663.98.2.282

Vygotsky, L. S. (1981). The genesis of higher mental functions. In J. V. Wertsch (Ed.), The concept of activity in Soviet psychology (pp. 144-188). Armonk, NY: ME Sharpe.

Wenger, E. (1998). Communities of practice: Learning, meaning, and identity. Cambridge, UK: 380 Cambridge University Press.

Wertsch, J. V. (1991). Voices of the mind: A sociocultural approach to mediated action. Cambridge, MA: Harvard University Press.

\section{Additional Resources}

Renshaw, P., \& Brown, R. (2007). Formats of classroom talk for integrating everyday and scientific discourse: Replacement, interweaving, contextual privileging and pastiche. Language and Education, 21, 531-549.

This article identifies formats of classroom talk for integrating children's everyday language with the disciplinary languages of learning. In these different formats, student progress in understanding is gauged by the extent to which students' talking and thinking is replaced, interweaved with, privileged or generalized within the language of the discipline being learnt. This is a very handy article to help teachers see how classroom talk can influence student learning.

Pendergast, D., \& Main, K. (Eds) (2019). Teaching primary years: Rethinking curriculum, pedagogy and assessment. Sydney, AU: Allen \& Unwin.

This book offers evidence-based approaches to teaching and learning in the (primary) elementary years of schooling. The text explores the unique characteristics of elementary school-aged children and considers the language, mathematics, science, health and the humanities curricula in depth. The text highlights major challenges facing elementary education relating to the use of digital 
technology, the development of age-appropriate pedagogies, practising differentiated learning and the design of effective assessment.

Van de Walle, J.A., Karp, K., Bay-Williams, J. M. (2017). Elementary and middle school mathematics. Teaching developmentally. $9^{\text {th }}$ Edition. Boston, MA: Pearson Education Incorporated.

This book provides a helpful guide for Pre-K-8 teachers of mathematics. This text reflects the Common Core State Standards and NCTM's Principles to Actions, as well as the current Australian Curriculum: Mathematics. Emphasis is placed on teaching mathematics conceptually, in a problembased, developmentally appropriate manner that supports the learning needs of all students. 